\title{
A Barrier Can Reduce Competition over Teats in Pair-Housed Milk-Fed Calves
}

\author{
M. B. Jensen, ${ }^{\star 1}$ A. M. de Passillé, $†$ M. A. G. von Keyserlingk,ł and J. Rushen† \\ *Department of Animal Health, Welfare and Nutrition, Faculty of Agricultural Sciences, University of Aarhus, PO Box 50, \\ DK-8830 Tjele, Denmark \\ †Pacific Agri-Food Research Centre, Agriculture and Agri-Food Canada, Agassiz, British Columbia, V0M 1A0 Canada \\ $\ddagger$ Animal Welfare Program, University of British Columbia, Vancouver, British Columbia, V6T 1 Z4 Canada
}

\begin{abstract}
The objectives of this study were 1) to assess whether a barrier placed between 2 teat buckets would reduce displacements at the teat buckets during milk-feeding events, 2) to determine whether the length of the barrier would influence this effect, and 3) to determine whether the quantity of milk provided to the calves would further affect competitive behavior. In both experiments, male and female Holstein calves were housed in pairs and fed milk in adjacent teat buckets. Experiment 1 included 12 pairs of calves provided with either 8 or 5 $\mathrm{L}$ of milk/d and compared the effect of a short barrier placed between the 2 teat buckets (B) with the effect of no barrier (C) in a crossover design with 4 periods of $10 \mathrm{~d}$ each. Three pairs of calves on each of the 2 milk allowances were given the treatments in the order B, $\mathrm{C}, \mathrm{C}, \mathrm{B}$, whereas the other 3 pairs were given the treatments in the order C, B, B, C. The short barrier reduced the frequency of switches between teat buckets but did not affect the latency to initiate switching behavior. Calves provided $5 \mathrm{~L}$ of milk/d ingested their ration faster and had a shorter latency to initiate switching behavior, but their frequency of switching per milkfeeding event was not higher than that of calves fed 8 L. Experiment 2 examined the effect of the length of barriers placed on both sides of the teat buckets. Fortyeight calves had either long $(100 \mathrm{~cm})$, short $(46 \mathrm{~cm})$, or no barriers throughout the milk-feeding period. Three barriers (all of the same size) were placed in each pen; one was placed between the 2 teat buckets, another was placed on the right-hand side of the right bucket, and another was placed on the left-hand side of the left bucket. The long barriers doubled the latency to initiate switching behavior and greatly reduced the frequency of switching. Moreover, no calves were able to displace a calf successfully while it was consuming milk from a
\end{abstract}

Received August 17, 2007.

Accepted December 21, 2007.

${ }^{1}$ Corresponding author: MargitBak.Jensen@agrsci.dk teat bucket when the buckets were separated by the long barriers. In conclusion, barriers between teat buckets can reduce competition for milk among pair-housed calves, but the effects were strongest when using long barriers, which separated the teat buckets as well as the front half of the calf during a feeding event.

Key words: behavior, calf, housing, milk-feeding method

\section{INTRODUCTION}

Group housing of milk-fed calves has some advantages for calf welfare by allowing increased social contact and more communal space (Jensen, 2003), and it substantially reduces labor costs associated with calf rearing (Kung et al., 1997). However, there are disadvantages. Group-housed calves fed milk through artificial teats compete for access to teats and calves are also displaced from teats while feeding (von Keyserlingk et al., 2004; Jensen and Budde, 2006). Increased displacements can lead to a large variation in milk intake between calves. This problem may be exacerbated when the calves are fed small amounts of milk, because hungry calves frequently switch from one teat to another (de Passillé and Rushen, 2007). Furthermore, calves on low milk allowances in computer-controlled milkfeeding stations actively compete for access to milk (Jensen, 2006), whereas competition by ad libitum-fed calves is rare (O'Driscoll et al., 2006; De Paula Vieira et al., 2008). Practical methods are needed for reducing competition over teats in group-housed milk-fed calves.

Research on pigs and adult cattle shows that barriers that separate animals while feeding significantly reduce competition and increase feeding time (Bouissou, 1970; Andersen et al., 1999; DeVries and von Keyserlingk, 2006). The objectives of our study were 1) to determine whether a barrier placed between 2 teat buckets would reduce the frequency of competitive behavior and displacements from the teat during milk feeding of calves, 2) to determine whether the length of the barrier would influence this effect, and 3) to deter- 
mine whether the quantity of milk provided to the calves would affect competitive behavior.

\section{MATERIALS AND METHODS}

\section{General Methods}

Holstein dairy calves (males and female) were removed from their mothers $24 \mathrm{~h}$ after birth and placed into individual straw-bedded pens $(1.0 \times 1.4 \mathrm{~m})$ until at least $1 \mathrm{wk}$ old. Calves were fed $6 \mathrm{~L} / \mathrm{d}$ of colostrum for $3 \mathrm{~d}$, followed by $6 \mathrm{~L} / \mathrm{d}$ of whole milk split into 2 feedings at 0800 and $1700 \mathrm{~h}$ from $\mathrm{d} 4$ until they entered the experiment when the youngest calf was 1 wk old (experiment 1), and when the youngest calf in the block was 1 wk old (experiment 2). Concentrates (Grøn Kalv Valset, DLG, Copenhagen, Denmark; 18\% CP), hay, and water were offered ad libitum from d 1 of age. Calves were moved into the experimental building and placed in pairs into each of 12 pens ( 6 pens measuring $1.94 \times 2.15 \mathrm{~m}$ and 6 pens measuring $2.49 \times 2.15 \mathrm{~m}$ ). Pens were fitted with holders for 2 plastic buckets, each fitted with one teat (Peach Teat, Skellerup Industries Ltd., Christchurch, New Zealand). Teat buckets were placed in the pens immediately before delivery of milk and were removed 30 min after milk delivery. The buckets were placed into the holder with the tips of the teats protruding $29 \mathrm{~cm}$ into the pen, with $35 \mathrm{~cm}$ between the 2 teats. Milk was provided such that both calves had access to the milk simultaneously.

\section{Experiment 1}

Animals and Feeding. Twenty-four calves (age 19 $\pm 7.7 \mathrm{~d}$; BW $58 \pm 6.4 \mathrm{~kg}$; mean $\pm \mathrm{SD}$ ) were assigned to pairs of one female and one male, with a maximum age difference of 1 wk within each pair. The 12 pairs of calves were ranked according to age, and 3 age groups were defined. Within these 3 age groups, 2 pairs were randomly assigned to a high $(8 \mathrm{~L} / \mathrm{d})$ milk allowance and 2 pairs were randomly assigned to a low milk allowance ( $5 \mathrm{~L} / \mathrm{d}$ ). The first $6 \mathrm{~d}$ in the experimental building served as an adjustment period for the calves. Calves on the high milk allowance were initially provided $6 \mathrm{~L} / \mathrm{d}$, but this was increased by $0.5 \mathrm{~L} / \mathrm{d}$ for $4 \mathrm{~d}$ until the target amount of $8 \mathrm{~L} / \mathrm{d}$ was achieved. Calves receiving the low milk allowance were provided $5 \mathrm{~L} / \mathrm{d}$ beginning immediately after being moved to the experimental building.

Experimental Treatments and Design. Pairs of calves were used in a crossover design with 4 periods of $10 \mathrm{~d}$. Each pair of calves was subjected to 2 treatments: a barrier placed between the 2 teat buckets $(\mathbf{B})$ and no barrier $(\mathbf{C})$. Three pairs of calves on each of the 2 milk allowances were given the treatments in the order B, C, C, B, whereas the other 3 pairs were given the treatments in the order C, B, B, C. The plywood barrier protruded $46 \mathrm{~cm}$ into the pen (i.e., it protruded $17 \mathrm{~cm}$ further into the pens than the tips of the teats).

Behavioral Recordings. A video camera (TVCCD14OIR, Monacor, Bremen, Germany) was positioned over each of the 12 pens. The behavior of the calves was video recorded during the morning milk feeding on the last day of each of the four 10-d periods. The recordings began as soon as the calves had access to the milk and continued for $30 \mathrm{~min}$. For each calf, the behavioral elements defined in Table 1 were recorded continuously from the video recordings by one observer. In addition, we recorded the latency (from when the milk was poured) for the first calf of the pair to switch from the teat bucket from which it started to ingest milk (the initial bucket) to the teat bucket of the other calf (the other bucket). Finally, the number of switches of each of the calves from one teat to the other was counted.

Statistical Analysis. The duration of ingesting milk and of nonnutritive sucking, and the frequency of competitive contacts, displacing the other calf, and switching between teats were analyzed by a mixed model including the fixed effects of treatment (barrier, control), milk allowance (high, low), period (1, 2, 3, 4), and the interaction of treatment $\times$ milk allowance. Calf was the statistical unit, but the dependence between calves within a pair was taken into consideration by including pair as a random effect in the model. Carryover effects were included in an initial model, but were found nonsignificant $(P>0.10)$ and were excluded from the final model. Cross-sucking had many zero observations, and was transformed into a binary variable (presence or absence of the behavior) and analyzed by a $\chi^{2}$ test (Siegel and Castellan, 1988) for each observation period. The latency from the time that the milk was poured until the time the first calf in the pen initiated switching behavior (switched from sucking the initial teat bucket to sucking the other teat bucket) was analyzed by survival analysis. In the case of no switching, the observation was treated as censored. The model included the effect of treatment (barrier, control), and the analyses were performed separately for each of the 2 milk allowances in each of the 4 periods. The results are presented as the median and interquartile range along with the $\chi^{2}$ value of the log-rank test and the $P$ value (Klein and Moeschberger, 2003).

\section{Experiment 2}

Animals and Feeding. Forty-eight calves (age $24 \pm$ $9.5 \mathrm{~d}$ and weight $67 \pm 11 \mathrm{~kg}$; mean $\pm \mathrm{SD}$ ) were assigned by birth date to 2 blocks of 12 pairs of one female and one male, with a maximum age difference within pairs 
Table 1. Description of the recorded behaviors

\begin{tabular}{ll}
\hline Behavior & Description \\
\hline Ingesting milk & The calf is ingesting milk by sucking the teat of a teat bucket that contains milk. \\
The calf is sucking the teat of an empty teat bucket. & The sucking movements are performed with the teat in the mouth. \\
Nonnutritive sucking & The calf is sucking on the head (muzzle, ear, or skin), on the skin of the neck, or under the belly \\
(on navel, scrotum, or udder base) of another calf. \\
The sucking movements are performed with the body part in the mouth. \\
The calf is butting another calfs body with the forehead or pushing with the forehead or body \\
while this other calf is sucking on a teat. \\
The calf is causing another calf that is sucking on a teat to leave this teat as a consequence \\
of contact. Subsequently, the calf accesses the teat. \\
The calf stops sucking on one teat and moves to the other teat and starts sucking on that.
\end{tabular}

of $13 \mathrm{~d}$. Within block, the pairs of calves were ranked according to mean age, and 4 age groups were defined. The 3 pairs within age group were randomly assigned to 1 of the 3 treatments and fed $6 \mathrm{~L} / \mathrm{d}$ of whole milk according to treatment for $6 \mathrm{wk}$.

Experimental Treatments and Design. Three treatments were tested in this experiment: long barriers (LB), short barriers (SB), and no barriers (NB; control). The long barriers protruded $100 \mathrm{~cm}$ into the pen (i.e., $71 \mathrm{~cm}$ beyond the tips of the teats). The short barriers are as described above in experiment 1 . Three barriers (all of the same size) were placed in each pen; one was placed between the 2 teat buckets, another was placed on the right-hand side of the right bucket, and another was placed on the left-hand side of the left bucket. There was $17 \mathrm{~cm}$ from the teat to the barrier on both sides, and $35 \mathrm{~cm}$ between either 2 of the 3 barriers.

In addition, each pair of calves was subjected to a competition test during one of the morning feedings. In each case, the oldest calf in the pair was provided 1.5 $\mathrm{L}$ rather than the normal $3 \mathrm{~L}$ of milk.

Behavioral Observations on Normal Days. A video camera (TVCCD-14OIR, Monacor) positioned over each of the 12 pens continuously recorded the behavior of each pair of calves during the morning milk feeding. Recordings began when the calves gained access to the milk and continuing for 30 min once a week during wk 2, 4, and 6 of the experiment. From the video recordings, one observer scored the behavior described in Table 1 and the duration of each sucking event from both calves from each of the 2 teat buckets. Finally, the latency to initiate switching behavior (previously described in experiment 1) and the total number of switches between the 2 teat buckets were also recorded.

Behavioral Observations During Competition Tests. Using direct observations throughout the 30min feeding period, one observer scored the variables described in Table 1 for the older calf. In addition, the latency to initiate switching behavior, the total number of switches between the 2 teat buckets, and the duration spent ingesting milk from each of the 2 teat buckets were recorded.

Statistical Analysis of Behavior on Normal Days. For each calf and week of observation, the total duration of milk ingestion and nonnutritive sucking, the duration of milk ingestion and nonnutritive sucking directed toward the initial bucket, and the number of switches between teat buckets were calculated and used as input in the analysis. The data were analyzed by using a mixed model including the fixed effects of treat-

Table 2. Duration and frequency of behaviors (mean \pm SEM) during the first 30 min after the milk was poured into buckets for the 3 treatments of experiment $2^{1}$

\begin{tabular}{|c|c|c|c|c|c|}
\hline Item & \multicolumn{3}{|c|}{ Barrier treatment } & $F$-value & $P$-value \\
\hline \multicolumn{6}{|l|}{ Duration (min per $30 \mathrm{~min}$ ) } \\
\hline \multicolumn{6}{|l|}{ Ingesting milk } \\
\hline From either of the buckets & $3.97 \pm 0.38$ & $4.73 \pm 0.38$ & $4.21 \pm 0.38$ & $\mathrm{~F}_{2,20}=2.18$ & $P>0.10$ \\
\hline From the initial bucket & $3.97 \pm 0.41$ & $4.51 \pm 0.41$ & $4.04 \pm 0.41$ & $\mathrm{~F}_{2,20}=1.20$ & $P>0.10$ \\
\hline \multicolumn{6}{|l|}{ Nonnutritive sucking } \\
\hline From either of the buckets & $4.77 \pm 0.47$ & $3.73 \pm 0.47$ & $3.77 \pm 0.47$ & $\mathrm{~F}_{2,20}=1.61$ & $P>0.10$ \\
\hline
\end{tabular}

${ }^{1} \mathrm{LB}=$ long barrier; $\mathrm{SB}=$ short barrier; $\mathrm{NB}=$ no barrier. 
Table 3. Number of calves performing behaviors during the first $30 \mathrm{~min}$ after the milk was poured into buckets, for the 3 treatments (experiment 2$)^{1}$

\begin{tabular}{|c|c|c|c|c|c|}
\hline \multirow[b]{2}{*}{ Behavior, no. of calves } & \multicolumn{3}{|c|}{ Barrier treatment } & \multirow[b]{2}{*}{$\chi_{(2)}^{2}$} & \multirow[b]{2}{*}{$P$-value } \\
\hline & LB & SB & NB & & \\
\hline \multicolumn{6}{|l|}{ Cross-sucking } \\
\hline Week 2 & 6 & 8 & 8 & 0.67 & $P>0.10$ \\
\hline Week 4 & 6 & 10 & 8 & 2.00 & $P>0.10$ \\
\hline Week 6 & 9 & 8 & 7 & 0.50 & $P>0.10$ \\
\hline \multicolumn{6}{|l|}{ Contacting calf } \\
\hline Week 2 & 3 & 16 & 14 & 28.51 & $P<0.001$ \\
\hline Week 4 & 2 & 15 & 15 & 31.69 & $P<0.001$ \\
\hline Week 6 & 2 & 14 & 13 & 23.17 & $P<0.001$ \\
\hline \multicolumn{6}{|l|}{ Displacing calf } \\
\hline Week 2 & 0 & 15 & 12 & 32.00 & $P<0.001$ \\
\hline Week 4 & 1 & 15 & 16 & 39.56 & $P<0.001$ \\
\hline Week 6 & 2 & 13 & 12 & 18.79 & $P<0.001$ \\
\hline \multicolumn{6}{|c|}{ Ingesting milk from other calf's bucket } \\
\hline Week 2 & 0 & 5 & 3 & 5.70 & $P<0.01$ \\
\hline Week 4 & 0 & 3 & 4 & 4.35 & $P<0.05$ \\
\hline Week 6 & 0 & 4 & 3 & 4.35 & $P<0.05$ \\
\hline \multicolumn{6}{|c|}{ Nonnutritive sucking from other calf's bucket } \\
\hline Week 2 & 8 & 13 & 11 & 3.56 & $P<0.05$ \\
\hline Week 4 & 8 & 14 & 14 & 8.00 & $P<0.01$ \\
\hline Week 6 & 8 & 16 & 14 & 13.14 & $P<0.01$ \\
\hline
\end{tabular}

${ }^{1} \mathrm{LB}=$ long barrier; $\mathrm{SB}=$ short barrier; $\mathrm{NB}=$ no barrier. Data for each of the $3 \mathrm{wk}$ are given $(\mathrm{n}=48)$.

ment (LB, SB, NB), week of the experiment $(2,4,6)$, and the interaction of treatment $\times$ week. Block and pair were included as random effects in the model to take into account the dependence between the calves in the same block and calves within a pair, respectively. The covariance structure of repeated measures on the same calf was modeled by compound symmetry (assuming constant correlation between the repeated observations). The behavioral variables that included many zero observations (cross-sucking, competitive contacts, displacing calf, milk ingestion from other bucket, and nonnutritive sucking of other bucket) were transformed into binary variables and analyzed by $\chi^{2}$ test or by Fisher's exact test (Siegel and Castellan, 1988) separately for each observation week. The latency to initiate switching behavior was analyzed separately for each of the $3 \mathrm{wk}$ by survival analysis including the effect of treatment (LB, SB, NB). The results are presented as the median and interquartile range along with the $\chi^{2}$ value of the log-rank test and the $P$-value (Klein and Moeschberger, 2003).

Statistical Analysis of Behavior During Competition Tests. The duration of milk ingestion, the duration of nonnutritive sucking, and the number of switches between teat buckets were analyzed by using a mixed model including the fixed effects of treatment ( $\mathrm{LB}, \mathrm{SB}$, and $\mathrm{NB}$ ) and block. In addition, the duration of milk ingestion and nonnutritive sucking of the initial bucket was analyzed by using this model. The behavioral variables that included many zero observations (cross-sucking, competitive contacts, displacing calf, and milk ingestion from the other bucket), were transformed into binary variables and analyzed by $\chi^{2}$ test or by Fisher's exact test (Siegel and Castellan, 1988). The latency to initiate switching behavior was analyzed by survival analysis for the effect of treatment as described previously.

\section{RESULTS}

\section{Experiment 1}

The frequency of switches from one teat to the other was reduced when the barrier was present $(8.13 \pm 1.23$ vs. $12.76 \pm 1.25$ frequency/milk feeding; $F_{1,75}=10.07$; $P<0.01)$. The presence of the barrier had no significant effect $(P>0.10)$ on any of the remaining variables (total duration of milk ingestion and nonnutritive sucking, the duration of milk ingestion and nonnutritive sucking directed toward the initial bucket), and no interactions between barrier and milk allowance $(P>0.10)$ were found. Calves on a high milk allowance spent more time ingesting milk (6.25 \pm 0.47 and $3.23 \pm 0.46 \mathrm{~min} /$ feeding; $\left.\mathrm{F}_{1,10}=20.99 ; P<0.01\right)$ and less time engaged in nonnutritive sucking $(2.60 \pm 0.53$ and $4.79 \pm 0.52 \mathrm{~min} /$ feeding; $\left.\mathrm{F}_{1,10}=8.81 ; P<0.05\right)$. Cross-sucking was observed in $83 \%$ of the calves, and among these, the average duration per feeding event was 41 (11 to 32 ) $\mathrm{s}$ [median (interquartile range)]. However, the occurrence of cross-sucking was not affected either by milk allowance or by the presence of the barrier. 


\section{Experiment 2}

Behavior on Normal Days. There were no obvious effects of the presence of the short barriers on any variable (Tables 2 and 3). The presence of long barriers reduced the frequency of switching between teats but did not affect the total duration of time spent ingesting milk or the duration of time ingesting milk from the bucket used for the first feeding event (Table 2). The presence of the long barriers did not affect the duration of nonnutritive sucking but tended to increase the duration of nonnutritive sucking of the initial bucket (Table 2 ). The latency to switch between teats was longer for calves with the long barriers in wk $2\left(\chi_{(2)}^{2}=21.05 ; P\right.$ $<0.001)$, wk $4\left(\chi_{(2)}^{2}=20.23 ; P<0.001\right)$, and wk $6\left(\chi_{(2)}^{2}=\right.$ 22.12; $P<0.001$; Figure 1).

The presence of long barriers also reduced the number of calves ingesting milk from and performing nonnutritive sucking on the teat bucket of the other calf, and reduced the number of competitive contacts and displacements of the other calf from its teat (Table 3). The number of calves that performed cross-sucking was not affected by treatment (Table 3 ). Cross-sucking was observed in 44, 50, and 50\% of the calves in wk 1, 2, and 3 , respectively. Among the calves that performed cross-sucking, the average duration per feeding event [median (interquartile range)] was 63 (18 to 137) s, 66 (23 to 186) s, and 76 (8 to 157) s in wk 1, 2, and 3 , respectively.

Behavior During Competition Tests. When the calves were fed the reduced volume of $1.5 \mathrm{~L}$, the latency to switch between teats was longer with the long barriers [10.57 (5.15 to 30.00), 3.13 (2.63 to 3.98), and 3.00 (2.63 to 3.38) $\min$ for $\mathrm{LB}, \mathrm{SB}$, and $\mathrm{NB}$, respectively (median and interquartile range); $\chi_{(2)}^{2}=11.00 ; P<$ 0.01]. During the competition test, teat switching was reduced with the long barriers (Table 4). Furthermore, no calf provided $1.5 \mathrm{~L}$ was observed to ingest milk from the other bucket when the long barriers were in place; however, this did occur 5 times in both the SB and NB treatments $\left(\chi_{(2)}^{2}=8.57 ; P<0.05\right)$.

\section{DISCUSSION}

Our results suggest that a long barrier placed between teats may reduce competition over teats by group-housed, milk-fed calves. A short barrier reduced the frequency of switches between teat buckets among pair-housed calves in experiment 1 , but we did not find this effect in experiment 2 . In neither experiment did the short barrier substantially reduce competitive behavior of the calves over the teats. In contrast, a long barrier (that extended beyond the calves' heads) doubled the latency of the calves to switch teats, greatly reduced the frequency of switching, and eliminated the
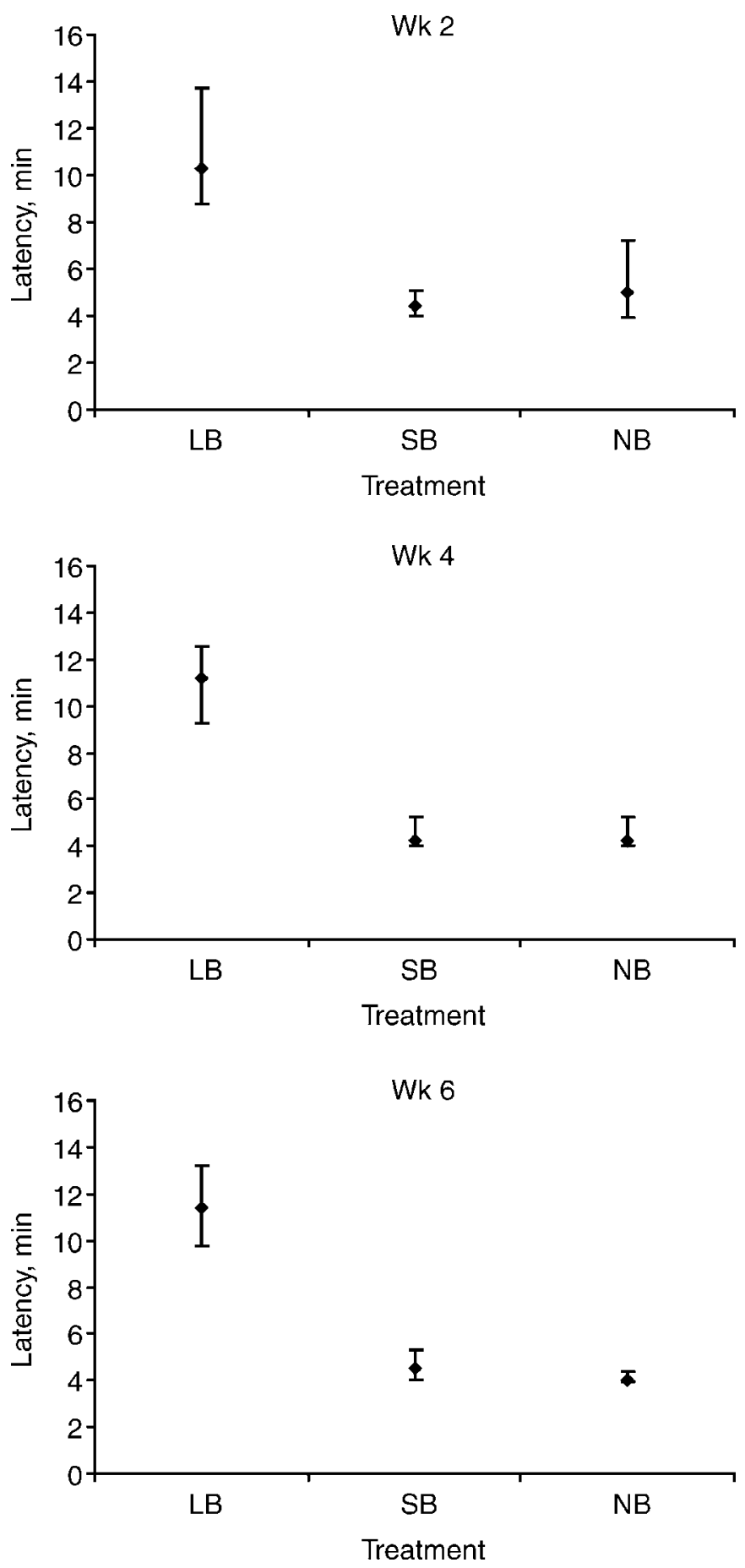

Figure 1. The latency to initiate switching behavior (median and interquartile range) for calves with long barriers (LB), short barriers (SB), or no barriers (NB) in wk 2, 4, and 6 of experiment 2.

number of calves displacing other calves during a feeding event. Increasing the milk allowance prolonged the milk meal and increased the latency to initiate switching behavior, but did not affect competitive behavior 
Table 4. Duration and frequency of behavior (mean \pm SEM) during the first 30 min after the milk was poured into bucket, for the 3 treatments, ${ }^{1}$ during tests where the test calf is given only half the normal volume of milk (experiment 2 )

\begin{tabular}{|c|c|c|c|c|c|}
\hline Item & \multicolumn{3}{|c|}{ Barrier treatment } & $F$-value & $P$-value \\
\hline \multicolumn{6}{|l|}{ Duration (min per 30-min) } \\
\hline \multicolumn{6}{|l|}{ Ingesting milk } \\
\hline From either of the buckets & $2.28 \pm 0.35$ & $2.86 \pm 0.35$ & $2.77 \pm 0.35$ & $\mathrm{~F}_{2,20}=0.77$ & $P>0.10$ \\
\hline From the initial bucket & $2.28 \pm 0.28$ & $2.18 \pm 0.28$ & $2.07 \pm 0.28$ & $\mathrm{~F}_{2,20}=0.15$ & $P>0.10$ \\
\hline \multicolumn{6}{|l|}{ Nonnutritive sucking, } \\
\hline From either of the buckets & $3.73 \pm 0.72$ & $2.84 \pm 0.63$ & $2.54 \pm 0.59$ & $\mathrm{~F}_{2,20}=0.88$ & $P>0.10$ \\
\hline
\end{tabular}

${ }^{1} \mathrm{LB}=$ long barrier; $\mathrm{SB}=$ short barrier; $\mathrm{NB}=$ no barrier.

over the teats. Neither the presence of the barrier nor an increased milk allowance reduced cross-sucking.

Separating the teat buckets with the long barriers clearly provided some protection from other calves attempting to gain access to the milk, but the short barriers were far less effective. Similar work has shown that aggression among feeding sows were greatly reduced when barriers that extended the length of the body were used as compared with when using barriers that only extended to the shoulder, or no barriers at all (Andersen et al., 1999). With the short barrier, only the heads of the calves were separated, whereas the long barrier separated the calves' heads as well as the front part of their body. In work undertaken by DeVries and von Keyserlingk (2006), the addition of partitions (feed stalls) between the bodies of adjacent cows provided protection while feeding and allowed for improved access to feed compared with feeding cows with no partitions. Moreover, the feed stalls also caused a change in the displacement strategy at the feed bunk, forcing cows to initiate contact at the rear of the animal they were attempting to displace rather than at the front or side, and this strategy was far less effective in displacing another cow. Unfortunately, we were not able to quantify how calves engaged in displacement behavior.

There are a number of reasons why long barriers may be more effective. With the long barriers, the calves had to move backward to get out from between the 2 barriers surrounding each teat bucket, thus increasing the effort required to switch between teats. Calves competing for milk from multiple teats may be viewed as foragers competing for patchy distributed food. According to the "patch model" (Krebs and Davis, 1981), an animal will leave a patch when its rate of intake falls below the average rate of intake. This corresponds to calves leaving the teat as a response to a reduction in milk flow as the bucket is emptying or as a response to a stoppage in milk flow when the bucket is empty. The model predicts that animals will feed for longer from the same (and depleting) patch when the travel time is increased. The larger effort required to switch between teats with the long barrier may represent an increased travel time, and this may result in the calf leaving its teat later.

Both types of barriers were blocking the calves' view of the other calf's head, whereas the long barriers were also blocking the view of the front part of the body. Calves butt as a response to a reduction in or stoppage of milk flow (Haley et al., 1998). When the calves butted the teat bucket, they came off the teat, and with short barriers they may have been able to see the other calf sucking on its teat. Thus, the short barriers may not have been as effective as the long barrier in blocking the calves' view of the other calf and the other teat bucket.

Calves switch teats during natural suckling on the dam (de Passillé and Rushen, 2007), and this behavior increases when they are hungry and when less milk is available (e.g., decrease or stoppage in milk flow). Teatfed calves will also increase teat switching when a second teat is available, and this switching is higher when both teats are of a slow flow rate (de Passillé and Gaboury, 2000). Thus, the behavior appears to be a natural attempt to increase milk intake by searching for a better teat. In our experiment, we found no evidence that increasing the milk allowance from 5 to $8 \mathrm{~L} / \mathrm{d}$ reduced teat switching. However, the calves on a low feed allowance ingested their milk in a little more than $3 \mathrm{~min}$, and the teat switching began at the end of the meal. However, in calves on a high feed allowance, the teat switching began, on average, 2 min before the calves finished ingesting milk (which was after a little more than 6 $\mathrm{min}$ ). Thus, the highly fed calves were switching teats even though there was still milk available in their teat buckets. This finding could be explained in terms of calves switching teats as a response to a decrease in milk flow when little milk was left in the bucket. Nevertheless, an alternative explanation is available. De Paula Vieira et al. (2008) found that calves offered a low milk allowance ingest their allotted portion in one continuous feeding bout, whereas calves fed ad libitum 
paused 4 to 6 times during a milk meal. Possibly the switching resulted from the calves exploring the alternative feed source during the pauses between feeding bouts because appetitive foraging may be performed both to obtain food and to obtain information about other food sources (Inglis et al., 2001).

Apart from supplying milk, the teat also has value as a stimulus for nonnutritive sucking after the milk is ingested, because calves are highly motivated to suck after drinking milk (de Passillé et al., 1992). In experiment 2, the use of the long barrier reduced nonnutritive sucking on the other bucket; the calves stayed at the initial teat to suck also after the milk was ingested. This may be an advantage because it helps ensure that the calf directs all its motivation for nonnutritive sucking toward the teat and not toward another calf. However, we found no effect on cross-sucking, perhaps because this did not occur at a high frequency.

The results of the present study show that by placing a physical barrier between the teats, the natural tendency of calves to switch teats may be reduced, but the barriers placed between the teats have to separate part of the body of the calf in addition to the head. The success of the long barrier in reducing switching behavior is most likely due to more effort being required to switch between teats, more difficulty in displacing the other calf, a better blockage of the calves' view, or a combination of all these factors.

\section{ACKNOWLEDGMENTS}

This experiment was conducted at Research Centre Foulum (Univ. Aarhus, Denmark). The study was recommended by the Nordic Joint Committee for Agricultural Research and supported by the Danish Ministry of Food, Agriculture and Fisheries. The authors would like to thank Erik L. Decker and John Misa Obidah for assistance.

\section{REFERENCES}

Andersen, I. L., K. E. Bøe, and A. L. Kristiansen. 1999. The influence of feeding arrangements and food type on competition at feeding in pregnant sows. Appl. Anim. Behav. Sci. 65:91-104.
Bouissou, M.-F. 1970. Role du contact physique dans la manifestation des relations hierarchiques chez les bovines. Ann. Zootech. 19:279-285.

de Passillé, A. M., and C. Gaboury. 2000. Factors that motivate a calf to switch teats during a nursing. Page 56 in Proc. 34th Int. Congr. Int. Soc. Appl. Ethol., Florianopolis, Brazil.

de Passillé, A. M., J. H. M. Metz, P. Mekking, and P. R. Wiepkema. 1992. Does drinking milk stimulate sucking in young calves? Appl. Anim. Behav. Sci. 34:23-36.

de Passillé, A. M., and J. Rushen. 2007. Calves' behaviour during nursing is affected by feeding motivation and milk availability. Appl. Anim. Behav. Sci. 101:264-275.

De Paula Vieira, A., and V. Guesdon, A. M. de Passillé, M. A. G. von Keyserlingk, and D. M. Weary. 2008. Behavioural indicators of hunger in dairy calves. Appl. Anim. Behav. Sci. 109:108-189.

DeVries, T. J., and M. A. G. von Keyserlingk. 2006. Feed stalls affect the social and feeding behavior of lactating dairy cows. J. Dairy Sci. 89:3522-3531.

Haley, D., J. Rushen, I. Duncan, T. Widowski, and A. M. B. de Passillé. 1998. Butting by calves (Bos taurus) and rate of milk flow. Anim. Behav. 56:275-285.

Inglis, I. R., S. Langton, B. Forkman, and J. Lazarus. 2001. An information primacy model of exploratory and foraging behaviour. Anim. Behav. 62:543-557.

Jensen, M. B. 2003. The effects of milk feeding method, milk allowance and social factors on milk feeding behaviour and cross-sucking in group housed dairy calves. Appl. Anim. Behav. Sci. 80:191-206.

Jensen, M. B. 2006. Computer-controlled milk feeding of grouphoused calves, the effect of milk allowance and weaning type. J. Dairy Sci. 89:201-206.

Jensen, M. B., and M. Budde. 2006. The effects of milk feeding method and group size on feeding behavior and cross-sucking in group housed dairy calves. J. Dairy Sci. 89:4778-4783.

Klein, J. P., and M. L. Moeschberger. 2003. Survival Analysis, Techniques for Censored and Truncated Data. Springer-Verlag, New York, NY.

Krebs, J. R., and N. B. Davis. 1981. An Introduction to Behavioral Ecology. 2nd ed. Blackwell Scientific Publications, Oxford, UK.

Kung, L., Jr., S. Demarco, L. N. Siebenson, E. Joyner, G. F. W. Haenlein, and R. M. Morris. 1997. An evaluation of two management systems for rearing calves fed milk replacer. J. Dairy Sci. 80:2529-2533.

O'Driscoll, K., M. A. G. Keyserlingk, and D. M. Weary. 2006. Effects of mixing on drinking and competitive behavior of dairy calves. J. Dairy Sci. 89:229-233.

Siegel, S., and N. J. Castellan. 1988. Nonparametric Statistics for the Behavioural Sciences. 2nd ed. McGraw-Hill, New York, NY.

von Keyserlingk, M. A. G., L. Brusius, and D. M. Weary. 2004. Competition for teats and feeding behavior by group housed dairy calves. J. Dairy Sci. 87:4190-4194. 